\title{
CONTEMPORARY ISSUES IN SOCIAL SCIENCES IN PAKISTAN
}

Hasan Askari Rizvi*

\begin{abstract}
The paper provides an overview of the evolution of Social Sciences with a focus on the Post-1945 period, known for major strides towards scientific, analytical, nonpartisan, multi-disciplinary and comprehensive study and research in different fields of Social Sciences. The paper discusses the gradual growth of Social Sciences in Pakistan in terms of increase in number of persons engaged in teaching, research and practice in various domains of Social Sciences, institutional facilities and availability of funds. There is a discussion of the major features of the research work done in Social Sciences in Pakistan and its weaknesses and deficiencies. The paper argues that Social Sciences have become important for societies like Pakistan that face different types of social and political conflicts. The rise of religious extremism, violence and terrorism also requires that we benefit from the work done in different fields of Social Sciences for understanding the dynamics of societal trends, issues and conflict and how to address them. The paper also reviews teaching and research being done in Pakistani universities, especially since 2005, when more funds became available for study and research in Social Sciences. The universities have vastly expanded their Doctoral and M.Phil. porgrammes but the imperative of quality is often neglected.
\end{abstract}

Keywords: social sciences, research approaches and methodologies, Pakistani universities, Higher Education Commission, higher research degrees

\section{Introduction}

Social Sciences are a product of human endeavor to know oneself and better understand human interaction with one another, society and its various formations, environment and the state. It is not simply an idealist statement on societal interaction but how and why human beings function in a particular manner in a social context. Another issue in Social Sciences pertains to the changing behaviorpatterns over a period of time. Social Sciences enable people to enhance their "understanding of social order, the process of social change and social stability and the causes underlying them" (Inayatullah, 2001, pp1-2). This understanding and knowledge helps to adopt measures to improve the milieu of societal interaction and social formations for its members.

\section{Literature Review}

Historically speaking, "all social knowledge was originally one and indivisible; the intellectual specialization of labor appears late upon the scholarly scene in the western world." It was from the classical Greek period to the $18^{\text {th }}$ century that "men basically saw each other not as specialists but as general seekers after wisdom and

${ }^{*}$ Hasan Askari Rizvi, Ph.D. Professor Emeritus, University of the Punjab, Lahore, Pakistan 
knowledge, as philosophers in the original sense of the word" (Easton D. 1965, p.11). With the proliferation of knowledge mainly in the $19^{\text {th }}$ and $20^{\text {th }}$ centuries, new avenues of study and research developed with specialization for the study of different aspects of human behavior in social and physical contexts. Today, Social Sciences comprise several semi-autonomous academic domains that focus on different dimensions of human behavior in varied social contexts. These academic fields explore how human being should interact with one another and organize the society as well as their actual behavior, i.e. how they actually go about functioning in different social contexts.

Social Sciences developed in North America and Europe in the $18^{\text {th }}$ and $19^{\text {th }}$ centuries as a part of human quest to know about oneself and the social and physical environment. We can also talk about old Chinese, the Middle Eastern and Indian writings. Initially there were historical narratives of different rulers, wars and description of societal features, including foods habits, dress and traditions and established social practices. The reports of travel to other lands provided useful information about people and their environment. Most colonized states were initially studied on modern lines by the scholars and bureaucrats of the colonial powers whose writings served as the basis for subsequent studies and analyses of these societies.

It was in the $20^{\text {th }}$ century, especially in the post- 1945 period, that greater attention was given to expanding Social Sciences with the objective of better understanding the society and its problems and for providing advisory to policy makers. The focus in Social Sciences shifted to the study of human beings and society in an objective, standardized manner so as to evolve widely applicable generalizations. The attempt was to create theories of wider application with scientific rigor. The effort was to adopt comparative and analytical approaches with greater use of empirical data that was subject to different modern techniques of research and analysis.

Various academic fields in Social Sciences began to employ the methods of physical and empirical sciences with the objective of a systematic acquisition of knowledge about people and society. The emphasis increased on theory building "through empirical observation which could be replicated and verified" (Kureshi, 2015). Much premium began to be assigned to collection of data through impersonal, retractable and cumulative processes for producing comparative and analytical studies.

Social Sciences experienced much intellectual growth under the rubric of Behaviorism, Post-Behaviorism and the subsequent intellectual movements for a comparative and comprehensive study of social phenomena. The focus is now on looking beyond the formal and legal institutions and processes in order to examine why and how people, institutions and processes actually perform their role. It is neither a moralist judgment nor a purely legal and constitutional study. Rather, an attempt is made to examine why and how the institutions and leaders function or behave in a particular manner. In the field of Political Science and International Relations the legalistic and moralist approaches are substituted by the dynamics of actual behavior of political players, institutions and processes. ${ }^{1}$ The key issue in

\footnotetext{
${ }^{1}$ See Iain McLean and Alistair McMillan
} 
political and societal processes is "Who gets what, when and how" (Harold D. 1958).

Social Sciences no longer pursue a single variable explanation. There is a clear preference for inter-disciplinary and multi-disciplinary approaches as well as the use of survey and quantitative techniques, using modern information and communication techniques. In some cases mathematical models are used by social scientists.

\section{Social Sciences in Pakistan}

Social Sciences in Pakistan have a mixed track record. There has been a significant increase in number of persons engaged in teaching, research and practice in various fields of Social Sciences. Similarly, institutional arrangements have also increased since Pakistan's independence in August 1947. There has been a large increase in public and private sector universities, area study centers, research organizations and think-tanks, government departments, non-governmental of organizations and individuals that are pursuing teaching, research and analysis. The pace of increase of such institutions and organizations was high in the 1970s and after the private sector was encouraged to set up universities and other institutions in the 1990s and the subsequent years. Foreign donors have also provided financial support to universities, think-tanks and non-governmental organizations for research and analysis and the holding of seminars and conferences from time to time. This practice has continued throughout Pakistan's history, although its pace increased after 2001. The setting up of the universities by the military also helped to expand teaching and research in selected Social Sciences.

We can identify useful and information based research and semi-research works done in different fields of Social Sciences. These provide important data, historical facts and analysis of the issues under study. Most of these studies are straight historical narratives, chronology of events, factual statements, description of evens or a disjointed collection of what others have written.

However, when it comes to seeking ground-breaking studies and analytical research in Social Sciences in Pakistan that gets international recognition, we have to make a real effort to identify such studies.

Major reviews of the development of Social Sciences in Pakistan, undertaken from the late-1980s to the beginning of the $21^{\text {st }}$ Century, express varying degrees of reservations on the overall quality of research in respect of basic data, comparative and analytical disposition, theory building and application of theory to concrete situations, generalizations of a wider application, methodological issues and scientific criteria. There are serious issues of poor objectivity or the selective use of data. In a large number of cases, personal wishes, ideological or political preferences have led to a selective use of historical evidence or a partisan interpretation of a situation which falters on a pure and simple test of logic. A part of this problem is due to the lack of full understanding of imperatives of depersonalized research based on recognized methodologies and comprehensive

(eds.), The Concise Oxford Dictionary of Politics (London: Oxford University Press, 2003), pp. 40-41. See also Graham Evans and Jeffrey Newnham, The Penguin Dictionary of International Relations (London: Penguin Books, 1998), pp.501-502 
data and also a lack of awareness about work done on similar issues elsewhere. This limits the capacity of a researcher to recognize multiple approaches to study of socio-political, cultural and economic issues and problems.

Dr. Mohammad Waseem complains about "the lack of theory in our Social Science teaching and research" which results in what he describes as "hyper factualism." He also laments that the education system in Pakistan has not been able to get away from the "prescriptive and moralistic approach to knowledge" (Waseem, M. 2001, p.80). Inyatullah (1989) argues that a large part of research is "historical, legal and formal" that is often "superficial, speculative [and] journalistic" in quality. He offers six principles of evaluating Social Sciences in Pakistan. These are:

1. "Adherence to scientific methodology"

2. "Extent of objectivity"

3. "Extent of creativity"

4. "Structural integration of Social Science knowledge"

5. "Extent of institutional capability for development of social sciences"

6. "Social utility of social sciences"

Zaidi (2003) maintains that "the state of Social Sciences in Pakistan is in a depressingly decrepit state." He, however, expressed some hope for the improvement in the study and research in Social Sciences in the $2^{\text {nd }}$ decade of the $21^{\text {st }}$ Century (DAWN, 6.1.2015). Saigol (2005) describes the quality of academic research in Social Sciences as "low to average" (p.471). Husain (2008) has talked about the inability of Social Scientists to contribute to the debate on public policy issues and that there is a shortage of "sound empirical studies" that offer "pragmatic and actionable" solutions to public policy problems. An opposite view argues that the effort to be relevant to policy makers undermines the autonomy and academic quality of Social Sciences. Social Scientists engage in search for solutions rather than searching for knowledge (Zaidi, 2002). A review of teaching and research in Political Science points out four major deficiencies which are applicable to other Social Sciences. These include neglect of inter-disciplinary approaches; shortage of teachers with academic excellence and dynamism; paucity of $r$ funding for research; and the non-availability of academic studies and research on many important issues and problems afflicting the society. ${ }^{2}$

\section{Importance of Social Sciences}

The policy makers have traditionally ignored or downplayed the importance of Social Sciences. They think that their interaction with people and the bureaucratic experience give them a better understanding of society than what academicians and researchers suggest. At the societal level, there is a widely shared perception that these academic disciplines offer limited job prospects to young people. Consequently, the governments assign little, if any, salience to Social Sciences and make limited funds available for research and writing in Social Sciences.

It is an erroneous assumption that Social Sciences have a limited relevance to governance and societal management. The research and analysis in various fields of

\footnotetext{
${ }^{2}$ Kundi, Mansoor Akbar, "The Teaching of Political Science in Pakistan," Dawn, February 8, 2004. The following book examines the quality of teaching and research in the major academic fields in Social Sciences: Inayatullah, Rubina Saigol and Pervez Tahir (eds.), Social Sciences in Pakistan: A Profile.
} 
Social Sciences focuses on the study of human beings and their behavior in different contexts, their interaction with one another as well as with physical and societal environment and different authority patterns that exist in a society, including the state governance system. These academic disciplines also study societal disharmony and conflict; customs and traditions; the process of change; political and societal choices; and the changing demands of people on the state and society. The interaction between different societies and especially social and physical mobility and their impacts on individuals and society are examined.

The data and analysis provided by social scientists on these and other issues is useful for policy makers in adopting policy-measures for effective governance and prudent socio-political and economic management The policy makers are better placed to make policies for addressing societal problems and satisfying the demands and needs of people.

Most developing states, including Pakistan face serious challenges to societal harmony and viability of the political and economic system. Social Sciences can make a critical analysis of societal diversity based on ethnicity, language, region, religion and its sub-divisions and other sources of conflict and violence and offer options and guidelines to cope with these challenges.

Religious and cultural extremism and terrorism threaten Pakistan's internal harmony and stability. Social Sciences offer professional skills and orientations to identify the root cause of these problems and their negative impacts on the society and the state and also suggest ways and means to manage these problems provided the policy makers are willing to benefit from such studies and engage in policy making and enforcement in their backdrop. The concepts and strategies of community building, inclusive and participatory development and empowerment of the people are major areas of study and research in Social Sciences.

Social Sciences can also suggest ways and means for promoting tolerance and democratic culture which are pre-requisites for making democracy sustainable and meaningful to the life of the common people rather than keeping it as an elite struggle for control of state apparatus and resources.

Most post-colonial states, including Pakistan, face the problems of establishing a commonly shared national discourse to build a national identity and resilience. What is a nation's heritage and how to construct a national identity in a manner that the socio-cultural and regional diversities become a source of strength? This is done partly by adopting an inclusive and participatory political and economic approach and partly by society's own experience that the nation-state and its processes work to their benefit by expanding their opportunities. Social Sciences can evolve the guidelines and approaches for cultivating such a shared historical, intellectual and emotional disposition for nation-building in a participatory and inclusive framework.

Social Sciences help to comprehend and manage societal deficiencies and all kinds of conflict. A person well versed in Social Sciences is mentally better prepared to cope with societal inequities and conflicts; not getting overwhelmed by these problems but trying to address these at the individual and collective levels. This means that such a person is not expected to be easily vulnerable to extremist appeals and violent solutions. Pakistan's experience of religious extremism and terrorism 
suggests that the young people with strong grounding in Social Sciences have a lesser probability of joining the extremist, violent or sectarian organizations than those with narrow religious orientations from early age socialization or family's religious traditions as well as those with a background in hard sciences, technology, medical, business and IT education. The latter have little orientations to cope with societal injustice, conflicts and extremist appeals.

Professor Sharif-al Mujahid underlines the importance of Social Sciences by arguing that these academic fields enable us to understand "the underlying currents of a certain social phenomenon and forecast its cost and consequences and influences for the society as a whole." He also maintains that Social Sciences "help us with the knowledge and skills to unravel the social fabric, place social issues and problems in their respective contexts, so that their solution could be arrived at methodically.",3

\section{Professionalism and Quality}

Social Sciences can be instrumental in promoting societal development, good governance and stable environment if social scientists ensure that their study and research maintains professional quality. The issues under investigation must be pursued in a dispassionate and non-partisan manner rather than simply creating a justification for serving the interests of the dominant elite in a society. Social Sciences must also fulfill the standardized methodological requirements of data collection, scientific analysis and research.

There is no single grand theory to study human beings and their mutual interaction. We talk of pre-theories, theories, paradigms, explanations and probabilities. There is a multiplicity of approaches and diversities of theories to study social phenomena. It is not desirable to pursue a single variable explanation of social problems and issues; multiple factor explanations and inter-disciplinary approaches that uphold scientific rigor and logic are more desirable. One must be willing to accept divergent explanations and that new facts, data and analytical tools can set-aside or update the existing explanations.

The collection of relevant data and its analysis and interpretation has to be done through known, established, impersonal and retractable ways. It must use what is described as the scientific method involving systematic theory building, internally consistent explanations based on observable evidence. One can also draw on the relevant research and analysis in other Social Science areas of study, at time borrowing from hard sciences. If needed statistical techniques and survey research can be used to add to scientific rigor.

The study and research in Social Sciences is an art as well as a disposition. It is an art because any one can learn the methods of scientific and analytical research through hard and persistent effort over the years. It is a disposition and orientation because it calls for cultivating a mental attitude that that keeps personal biases to the minimum. Personal belief system or puritanical ideological imperatives are not allowed to influence research and analysis. A good researcher cultivates a scientific, logical and analytical mindset to study social issues.

\footnotetext{
${ }^{3}$ Sharif-al-Mujahid, (December 12-13, 2015). "Significance of Social Sciences" The Concluding Address
} to the International Conference on Contemporary Social Sciences, University of Karachi 
The research and analysis in Social Sciences has to be comprehensive and comparative. The socio-economic and political problems have to be critically examined in the context of all possible explanations and how other societies have dealt with these or similar problems.

The quality of research cannot improve in Social Sciences unless the researchers imbibe the depersonalized and scientific disposition and adopt analytical and critical thinking which leads a person to look at the routine explanations. This calls for grasping research methodology, theory-building and analysis of specific cases in the western countries where Social Sciences have undergone much transformation over the last fifty years. There is no need to replicate all this but a researcher must examine the work done there to expand one's intellectual horizon and learn to develop a multi-factor and critical approach for analyzing social phenomena. It is also important to examine how far these methodologies, research techniques and theoretical formulations help a comprehensive and comparative critical analysis and can improvements be suggested on the existing research and writing on the subject under study?

The most challenging task is study and research in political history, cultural heritage, socio-economic issues as a part of the national identity formation process and the formulation of the nation-state oriented political and cultural narratives. These efforts are often influenced by personal biases, partisan interests and the imperatives of power politics. The writing of political and cultural history is tainted by the prevailing political considerations which determine what to include in and what to exclude from national history and heritage.

Those who want to dominate the present always endeavor to reconstruct the past to their advantage because history and heritage are employed for justifying present political and cultural agendas. The established principles of impersonal and scientific research are ignored and a two-fold process of partisan selection of historical evidence and rewriting of history is pursued to serve the present political needs of the dominant elite, especially the rulers. It is a common practice in most post-colonial states, including Pakistan, to engage in a selective use of historical evidence, an out of context interpretation of events and statements of historical personalities and the use of non-authentic evidence to support a partisan articulation of the national identity and culture.

Pakistan, like most post-colonial states, has undergone the process of writing and rewriting of history because the competing political interests wanted to write history to justify and advance their current political agendas. They made a selective use of history or gave self-serving interpretations to historical events and the role of key personality of the past, especially the leaders of the freedom movement. The issues that have been interpreted differently by different governments and political and religious groups include the factors shaping the demand for the establishment of Pakistan as an independent state, Pakistan's national identity and national ideology, the relationship between Islam and the Pakistani state, the national identity and regional/provincial identities and cultures, Quaid-i-Azam Muhammad Ali Jinnah's views on Islam and Pakistani state system, the Objectives' Resolution, and the institutional and legal arrangements of an Islamic State. 
In the post-1977 period, the military regime of General Zia-ul-Haq articulated the relationship between Islam and Pakistani state and society on conservative and fundamentalist lines. The 'Ideology of Pakistan' was declared synonym with the 'Ideology of Islam,' interpreting it with reference to the Muslim League slogans for the 1946 elections mainly in the Punjab rather than the Muslim League resolutions and that statements of Jinnah in their true context. ${ }^{4}$ Jinnah's address to the Constituent Assembly of Pakistan on August 11, 1947 continues to be a point-ofcontention between the competing interpretations of Pakistan's national identity. It would be an interesting study to compare the articulation of these issues under official and semi-official patronage in the pre-1977 and the post-1977 periods. The school-level text books published in the 1980s and later show a deliberate attempt to rewrite history, national culture, identity and ideology under the influence of the perceptions of the military regime and conservative religious elite. There was an attempt in the 1980s to "Islamize" Social Sciences as a part of an overall attempt to Islamize knowledge and academics in Pakistan. ${ }^{5}$

The writings on history, politics and culture of Pakistan have remained focused at the macro-level, the mainstream leaders of the nationalist movement and the federal and provincial level leadership and political developments in the post-independence period. There has been less attention towards writing regional, provincial and local history; political and social movements by ordinary people and local elite; literary and cultural history; and nationwide, regional and local languages. Much work is needed to be done in these fields satisfying the criteria of an in-depth, depersonalized, comprehensive, comparative and scientifically rigorous research and analysis.

Dr. Moonis Ahmar has concisely summed up the overall challenges to Social Sciences: "These range from hostility to indifference, lack of proper resources, conducive environment for research, availability of funds and lack of proper research skills and expertise" (Ahmar M. 2015. December).

\section{Recent Developments: 2005-2016}

A number of positive strides have been made by the federal and provincial governments and the Higher Education Commission (HEC) since 2002, and especially from 2005 onwards to promote teaching and research in Social Sciences at the post-graduate and graduate levels.

The United States withdrew its economic sanctions against Pakistan in OctoberDecember 2001 against the backdrop of Pakistan's decision to join the U.S.-led global effort to fight terrorism. U.S. funds became available in the post 2001 period, especially in 2005-2016. Other western states and Japan also adopted liberal approach for providing funding for Pakistan's socio-economic development.

\footnotetext{
${ }^{4}$ On problems and issues in writing and rewriting of Pakistan's history, politics and culture, see the writings of Sharif-al-Mujahid, Ayesha Jalal, K.K. Aziz, Mubarak Ali, Syed Jaffar Ahmed and Hasan Askari Rizvi.

${ }^{5}$ See, for example, Anis Ahmad, "Some Methodological Problems in Islamization of Social Sciences," in S.H. Hashmi, The State of Social Sciences. PP.89-96. Akbar S. Ahmad, Towards Islamic Anthropology (Herndon, VA: International Institute of Islamic Thought, 1986. (A Pakistani edition was published in 1987 by Vanguard Books, Lahore.). Muhammad Amin, "Reconstruction of Humanities in Islamic Perspective: A Case Study of Pakistan." Journal of Department of Islamic Thought and Civilization (University of Management and technology, Lahore), Vol.2 No.1. Spring 2002, pp.37-55.
} 
The U.S. AID provided financial support to several projects in the education sector and the U.S. extended the scope of the Fulbright Educational Programme, turning it into the biggest programme in a single country. There were other fellowships and visits programmes sponsored by the U.S. Some other countries also made academic funding and scholarships available for higher education. The government of Pakistan/HEC and some state universities provided financial support for higher education abroad. The teachers and researchers in various fields of Social Sciences benefited from these expanded opportunities.

A number of foreign foundations and thinks tanks maintain links with Pakistan's academia, hold joint academic programs and contribute financially to academic activities, including the holding of national and international conferences and seminars.

In the domestic context, the HEC and the state universities have launched several programmes for improving teaching and research in Social Sciences. These include:

1. Monetary rewards and academic honours for research and teaching work.

2. The holding of conferences and seminars. Special financial grants for university faculty to present research papers in conferences abroad.

3. An increase in the publication of research journals by university departments and faculties.

4. Introduction of new courses in the existing academic programs and the launching of new degree or diploma programs; replication of the morning/regular Master's programs in afternoon, evening and weekend. Some university departments have also introduced new 4-year BS programs.

5. The expanded local PhD and MPhil programs. Financial support to the students for doctoral studies.

6. Increased financial support to the university faculty for higher education abroad

While appreciating the availability of new opportunities for improvement of academic qualifications, research and teaching in Social Sciences, it is important to recognize the importance of academic excellence rather than pursuing a mechanical approach of quantity or numbers to highlight the success of the new academic ventures. Further, these new academic ventures have been going on for the last over ten years, it is therefore necessary to undertake an independent evaluation of their output. $^{6}$

The most challenging issue for the new academic strides is how to ensure professional excellence when a teacher has to teach several courses at the post graduate level, supervise M.A., M.Phil. and PhD theses? In some cases, senior faculty members supervise over 15 theses at one time, in addition to performing a number of other tasks. They are also expected to do their own research and publish quality research papers. Why do not we recognize the limits of human capacity?

\footnotetext{
${ }^{6}$ For a brief overview of the HEC initiated local $\mathrm{PhD}$ programme and some concerns about its quality, see Grace Clark, "Reform in Higher Education in Pakistan," in Robert M. Hathaway (ed.), Education Reform in Pakistan: Building for the Future (Washington, D.C.: Woodrow Wilson International Center for Scholars, 2005), pp.55-69 (see pp.57-60).
} 
As the research journals have proliferated in Pakistani universities over the last ten years, it is difficult to suggest if this increase has equally augmented the quality of published research articles. The quality of published material is uneven and it seems that these journals do not give equal importance to quality; some hardly pay any attention to copy-editing of the articles, although the HEC requirement of peer review is invariably fulfilled. There is a noticeable increase in research articles carrying several names as authors even if there is no survey research and no multiperson research project. In a good number of cases, a name is added as a co-author to oblige someone, described as a "gift" authorship. In some cases the name of a senior faculty appears as the first author in two-three co-authored articles published in one issue of the departmental journal. How far the proliferation of universitybased research journals has contributed to producing world quality literature in different fields of Social Sciences? At the international level, university linked research journals are known for producing quality and trend setting analysis and research. How many of the research journals linked with Pakistani universities can be placed in this category?

From time to time there are complaints from academic institutions about plagiarism in research papers and $\mathrm{PhD} / \mathrm{MPhil}$ theses. The universities and the HEC have found it difficult to deal with this issue, although a mechanical approach of relying on a special software is employed to identify repetitions and duplications in articles and theses. Why has this problem increased now? However, while controlling this kind of academic dishonesty, make sure that the plagiarism issue is not used for witchhunt of academicians (Nadeem ul Haq 2015; Munawar A.A. \& Maryam I. 2015).

The expanded $\mathrm{PhD}$ and M.Phil programmes have enabled a good number of young people to get these degrees. The universities departments have more faculty with these degrees than was the case in the pre-2005 period. However, the $\mathrm{Ph} . \mathrm{D}$. program is based on an erroneous assumption that the increase in the number of PhDs will improve the quality of education in Pakistani universities. ${ }^{7}$ Over ten years down the road, how far the study and research in Social Sciences have acquired greater excellence because there are more local $\mathrm{PhDs}$ available?

The quality of education and research cannot improve by turning Pakistani universities into factories for producing M.Phil. and Ph.D. degree holders. The quality and excellence is more important for the Ph.D. degree than anything else. This criterion is not being adequately met. There are individual cases of quality work. However, the accumulative impact of so many Ph.Ds. is far from satisfactory (Yasir P. 2015). How many of these PhD theses have turned out to be the studies of international stature on the problems and issues relating to Pakistani state and society $?^{8}$

A large number of Ph.D. and M.Phil. in the fields of International Relations, Political Science and Pakistan Studies in a number of state universities are being done on the post-September 2001 regional and global situation, focusing on the

\footnotetext{
${ }^{7}$ Addressing the $17^{\text {th }}$ convocation of the Lahore University of Management Sciences (LUMS) in December 2005, President General Pervez Musharraf said: "It was shameful for a country with nuclear and missile technology to have a few dozen PhDs back in 1999. Now we have more than $700 \mathrm{PhDs}$ and after two years the country will produce 1500 PhDs every year." Dawn, December 30, 2005.

${ }^{8}$ See an evaluation of the PhD programme, Pervez Hoodbhoy, "Enough Ph.Ds, Thank You" Dawn, November 21, 2015
} 
relations and issues among Pakistan, the U.S., Afghanistan, India and China, terrorism and counter terrorism and related issues. These are important questions to be addressed. However, one wonders how much original and quality Ph.D. level research can be done on a situation that is still unfolding? Further, very few, if any, official record, primary sources and public documents are available for such studies.

The Ph.D. level research should focus primarily on basic research to fill the gaps in the existing literature on Pakistan and Pakistanis in each area of study in Social Sciences. This will contribute to accumulation of knowledge and research on Pakistan. However, such studies must meet the established academic standards and make a noticeable addition to the existing literature in respect of data, analysis and theoretical formulations.

\section{Concluding Observations}

It is no longer possible to talk of the dismal state of Social Sciences in Pakistan. However, it is difficult to be fully upbeat about the state of affairs in different domains of Social Sciences. There are serious issues of quality research and analysis. Only a small number of studies meet the established criteria of comprehensive, comparative and standardized methodological requirements for data collection, analysis and narrative building.

The opportunities and facilities for teaching, study and research in various fields of Social Sciences have increased since 2001. More funding is available for research and academic work than was the case in the last century; although in absolute terms the available funding is far less than the requirements of a world class teaching and research.

There is a need to pay more attention to strengthening Social Sciences research because it can contribute positively to addressing the problems of religious and cultural intolerance and terrorism. It can also help to project Pakistan's soft image abroad. The academia and research in Social Sciences are what is described as the "soft power" to attract and persuade other nations to Pakistani state and society (Joseph S. N. 2004).

The highest priority for research and analysis should be assigned to quality rather than quantity. Social sciences cannot improve simply by publishing more journals and research articles. Similarly dishing out the PhD degrees will not help. There is an urgent need of a thorough evaluation of the quality of research journals and especially the $\mathrm{PhD}$ programme to ensure academic excellence. The key issues are the annual intake of student to $\mathrm{PhD}$ studies, quality of supervision and how many theses a teacher can supervise concurrently?

The research must fulfill the well-established norms of scientific rigor, impersonal and retractable data collection and a comparative and comprehensive analysis that is internally consistent and helps theory building. It should not only offer a critical appraisal of the problems and issues but must also show its relevance to problem solving. All this is an ever-present challenge for social scientists in Pakistan.

\section{References}


Ahmar, Moonis (2015, 12-13 December). "Reconceptualizing Social Sciences.” (A paper presented at the International Conference on Contemporary Social Sciences, University of Karachi).

Easton, David (1965). A Framework for Political Analysis, Englewood Cliffs, N.J: Prentice Hall.

Harold D. Lasswell (1958). Politics: Who Gets What, When, How, New York: World Publishing

Husain, I. (March 27, 2008). Public Policy and Social Sciences, A paper presented at the Workshop on Social Sciences organized by Government College University, Lahore. Unpublished.

Inayatullah (2001). "Social Sciences in Pakistan: An Evaluation," in S.H. Hashmi (ed.), The State of Social Sciences in Pakistan, Islamabad: Council of Social Sciences Pakistan.

Inayatullah, (November 1989,). "Social Sciences in Pakistan: An Evaluation," in S. H. Hashmi, The State of Social Sciences, p.13. An earlier version of this article was published in International Social Science Journal, Vol.XLI, No.4, pp.617-633.

Joseph S. Nye, Jr. (2004). Soft Power: The Means to Success in World Politics, New York: Public Affairs

Kureshi, Ahsan. (October 21, 2015). "Rooting Specialized Social Sciences," Nation, Lahore

Munawar A Anees and Maryam Iraj, (August 2, 2015). "Plagiarism: The Plague of Pilferage." Express Tribune, Karachi

Nadeem ul Haque (July 23 and 24, 2015). "Plagiarism is but One Symptom.” News.

Pirzada Y. (July 8, 2015). “Kagzi Universtian” (Paper Universities), Jang, Karachi

Saigol, R. (2005). "Conclusions,” in Inyatullah, Rubina Saigol and Pervez Tahir (eds.), Social Sciences in Pakistan: A Profile, Islamabad: Council of Social Sciences Pakistan.

Waseem, Mohammad (2001). "Underdevelopment of Social Sciences in Pakistan," in S.H. Hashmi (ed.), The State of Social Sciences in Pakistan

Zaidi S. A. (2003), 'The Dismal State of Social Sciences in Pakistan,' in S. Akbar Zaidi (ed.), Social Sciences in Pakistan in the 1990s, Islamabad: Council Social Sciences Pakistan p. 225

Zaidi, S. A. (November 6, 2015). A report of talk in Karachi by Haneen Rafi, Dawn, Karachi

Zaidi. S. A. (December 15, 2002). A future in Need of Rescue?, News, Lahore. 